\title{
A meta-analysis of the effectiveness of gradual versus abrupt smoking cessation
}

\author{
Jixiang Tan', Lin Zhao', Hong Chen ${ }^{2}$
}

\begin{abstract}
INTRODUCTION The aim of this review is to test whether a gradual reduction in smoking results in a superior quit rate compared to abrupt cessation.

METHODS This review was based on Cochrane methodology for conducting metaanalysis. Only randomized controlled trials were eligible for this review. The participants were adult smokers who were addicted to tobacco, defined as those who smoked at least 15 cigarettes or 12.5 grams of loose-leaf tobacco daily or who had an end-expiratory carbon monoxide concentration of at least $15 \mathrm{ppm}$. Both groups used an equal amount of nicotine replacement therapy (NRT) before and after quitting smoking. The Review Manager Database (RevMan version 5.3) was used to analyze selected studies.

RESULTS Three randomized controlled trials involving 1607 patients were included. The prolonged abstinence rate of the gradual cessation group was significantly lower than that of the abrupt group (relative risk, $\mathrm{RR}=0.77$ ). The result of 7 -day smoking cessation rate was also lower in the gradual group $(\mathrm{RR}=0.76)$.

CONCLUSIONS Comparing the combination of NRT and abrupt cessation, the smoking cessation rate of the combination of NRT and gradual cessation is significantly lower. No significant adverse events were found in either group.
\end{abstract}

\section{AFFILIATION \\ 1 Department of Emergency \& Critical Care Medicine, The First Affiliated Hospital of Chongqing Medical University, Chongqing, China 2 Department of Orthopedics, The First Affiliated Hospital of Chongqing Medical University, Chongqing, China \\ CORRESPONDENCE TO Hong Chen. Department of Orthopedics, The First Affiliated Hospital of Chongqing Medical University, Youyi Road, Yuanjiagang Yuzhong District 400016 Chongqing, China. E-mail: 22082800@qq.com}

KEYWORDS

smoking cessation, metaanalysis, gradual, abrupt

Received: 1 November 2018 Revised: 3 December 2018

Accepted: 6 December 2018

\section{INTRODUCTION}

Tobacco smoking is a leading cause of mortality in developed and developing countries ${ }^{1}$. Most smokers, at sometime, have considered quitting. For those smokers interested in quitting, deciding between a gradual decrease or an abrupt quitting method is a common concern ${ }^{2,3}$. Two recommended quit methods in standard cessation programs involve either a gradual reduction of smoking before complete abstinence or abrupt abstinence from cigarettes.

Worldwide guidelines for smoking cessation generally recommend abrupt cessation and do not support a gradual reduction in smoking ${ }^{4-6}$. However, many surveys show that smokers are more likely to choose to stop gradually ${ }^{2,3,7}$. It may be more acceptable to gradually reduce smoking addiction.

Several observational studies found that smoking abstinence rates were higher in smokers who quit abruptly than in those who quit gradually ${ }^{2,8,9}$. However, in these studies, associations may be explained by confounding variables, such as research methods, motivation to quit, self-efficacy, dependence level, or the amount of support received. Those who used the gradual method may have been less likely to receive professional support, since most treatment guidelines do not recommend gradual cessation ${ }^{10,11}$. It is also possible that the lower quit rate in those who quit gradually is explained by adverse self-selection if 
smokers chose the gradual method only after having failed with the abrupt method. This review aims to test whether an initial gradual reduction in smoking results in a superior quit rate compared with abrupt cessation.

\section{METHODS}

This review was based on Cochrane methodology for conducting meta-analysis ${ }^{12}$.

\section{Search strategy}

The published literature was searched using the electronic databases MEDLINE (1950 to December 2018), AMED (1985 to December 2018), EMBASE (1974 to December 2018), CINHAL (1982 to December 2018), Cochrane Library (2018), CNKI (1994 to December 2018), Scopus and Biomed Central. No language or date restrictions were applied. The Medical Subject Headings (MeSH) and keyword search adopted was 'smoking cessation' AND 'abrupt' OR 'gradual'. The unpublished literature was searched using the electronic databases OpenSIGLE (System for Information on Grey Literature in Europe), the WHO International Clinical Trials Registry Platform, Current Controlled Trials, UKCRN Portfolio Database and National Technical Information Service, from their inception to 1 August 2018. Finally, the reference lists of all full-text papers identified as pertinent to the study were reviewed for any unidentified studies.

\section{Inclusion criteria}

Only randomized controlled trials (RCTs) were eligible for this review, with an experimental group that used the gradual method to stop smoking and a control group that received an abrupt method. The participants were adult smokers who were addicted to tobacco, defined as those who smoked at least 15 cigarettes or 12.5 grams of loose-leaf tobacco daily or who had an end-expiratory carbon monoxide ( $\mathrm{CO}$ ) concentration of at least $15 \mathrm{ppm}$.

Both groups used an equal amount of nicotine replacement therapy (NRT) before and after quitting smoking. In the gradual group, participants aimed to gradually reduce the number of cigarettes smoked within a certain period. The participants of the abrupt group were set a cessation date to quit directly. To ensure the reliability of the results, end-expiratory $\mathrm{CO}$ concentrations were only used to check whether the participant quit smoking.

\section{Study selection}

Two authors (TJX, ZL) independently applied the search strategy to selected references from these databases. The titles and abstracts of those articles were reviewed independently. When there was a doubt, the full text was retrieved for further scrutiny. Those two authors independently assessed each full study report to see whether it met the inclusion criteria, and authors were contacted for more information and clarification of data as necessary. Any disagreement was discussed with the senior author $(\mathrm{CH})$, and when consensus could not be reached, that study was excluded. A list of all pertinent papers satisfying these criteria was then constructed by each reviewer, to compile an agreed list of studies.

\section{Data extraction}

A data extraction form was designed and agreed by the authors, and a pilot test of three articles was performed to ensure its consistency. Initially, two authors (TJX, ZL) independently extracted the data, which was later reviewed jointly to produce agreed accurate data. Disagreements were resolved by consensus or consultation with the senior authors. Data extracted included: sample size, study design, subject age, gender, body mass index, highest education, cigarettes per day, minutes to the first cigarette of the day, cigarette type, cigarette dependence scale, age started smoking, prior quit attempts, prior treatments, and confidence in the ability to quit.

\section{Outcome}

The outcome measures were the prolonged and 7-day $\mathrm{CO}$-verified abstinence rates, and other adverse events.

\section{Quality assessment}

To assess the methodological quality of included studies, author (JXT) used the Jadad score ${ }^{13}$, including the proper conduct of randomization, concealment of treatment allocation, the similarity of treatment groups at baseline, clinician blinding, and the description of withdrawals and dropouts. The methodological quality of each trial was scored and ranged from 0 to 5 . Any disagreement was resolved by the senior authors. 


\section{Statistical analysis}

The Review Manager Database (RevMan version 5.3, Cochrane Collaboration, The Nordic Cochrane Centre, Copenhagen) was used to analyze selected studies. Continuous data for each arm in a particular study were expressed as mean and standard deviation (SD), and the treatment effect as mean differences. Dichotomous data for each arm in a particular study were expressed as proportions or risks, and the treatment effect as relative risk (RR). Missing data were sought from the authors. When this was not possible, or data were missing through loss to followup, intention-to-treat principles were used. Statistical heterogeneity was assessed using the value of $\mathrm{I}^{2}$ and the result of the chi-squared test. A p-value less than 0.1 and an $\mathrm{I}^{2}$ value greater than $50 \%$ was considered suggestive of statistical heterogeneity, prompting random effects modelling estimate. Otherwise, a fixed effects approach was used. Conversely, a nonsignificant chi-squared test result $\left(\mathrm{p} \geq 0.1\right.$ and an $\mathrm{I}^{2}$ $\leq 50 \%$ ) only suggested that there was no evidence of heterogeneity; it did not imply that there was necessarily homogeneity, as there may have been insufficient power to be able to detect heterogeneity. When the data allowed, we performed a subgroup analysis of the trials.

\section{RESULTS}

A total of 134 abstracts and titles were reviewed.
Figure 1. Flowchart of the study selection

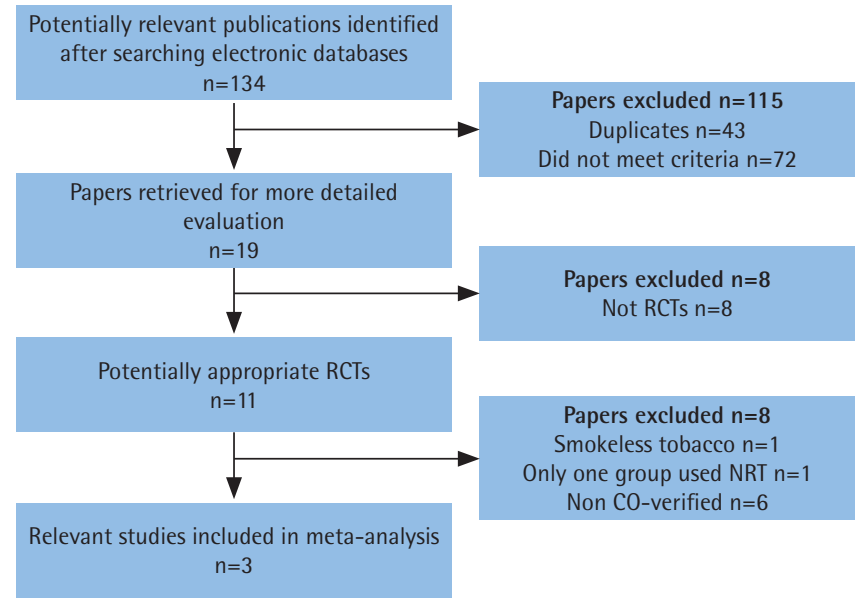

RCT: randomized controlled trial, NRT: nicotine replacement therapy, CO: carbon monoxide, $\mathrm{n}$ : number of papers.

Of these, 3 satisfied the eligibility criteria and were included in the meta-analysis ${ }^{14-16}$. A flowchart is provided in Figure 1. The number of participants included in these RCTs ranged from 314 to 697 . A total of 1607 participants were enrolled in the RCTs. The details are shown in Table 1 . These studies were relatively well designed with a quality assessment score of 5 (score range 0-5). A funnel plot based on the most frequently cited outcome was broadly symmetrical, indicating minimal publication bias (Figure 2).

\section{Table 1. Characteristics of the included studies}

\begin{tabular}{|c|c|c|c|c|c|c|c|c|c|c|}
\hline Author & Groups & $\begin{array}{c}\text { Number } \\
\text { (in) }\end{array}$ & $\begin{array}{l}\text { Age } \\
\text { (vears) }\end{array}$ & $\begin{array}{l}\text { Cigarettes } \\
\text { per day } \\
\text { (n) }\end{array}$ & Intervention & NRT type & $\begin{array}{l}\text { Prolonged } \\
\text { abstinence } \\
\text { rate }\left({ }^{\circ}{ }_{0}\right)\end{array}$ & $\begin{array}{l}\text { Dropout } \\
\text { rate }\left({ }^{\circ}\right)\end{array}$ & Year & Jadad \\
\hline \multirow{2}{*}{$\begin{array}{l}\text { Lindson- } \\
\text { Hawley }^{14}\end{array}$} & Gradual & 342 & 49.0 & 20.0 & \multirow{2}{*}{$\begin{array}{l}\text { Reduced by } 50 \% \text { in the } \\
\text { first week, } 75 \% \text { in the } \\
\text { second week, and then } \\
\text { to quit. Set a cessation } \\
\text { date to quit directly. }\end{array}$} & \multirow{2}{*}{$\begin{array}{l}\text { Nicotine } \\
\text { patches }\end{array}$} & 15.5 & 17.3 & \multirow[t]{2}{*}{2016} & \multirow[t]{2}{*}{5} \\
\hline & Abrupt & 355 & 49.0 & 20.0 & & & 22.0 & 14.1 & & \\
\hline \multirow[t]{2}{*}{ Hughes $^{15}$} & Gradual & 297 & $48.0 \pm 13$ & $23.0 \pm 8$ & \multirow[b]{2}{*}{$\begin{array}{l}\text { Reduced by } 25 \% \text { in } \\
\text { the first week, } 50 \% \\
\text { in the second week, } \\
75 \% \text { in the third week, } \\
\text { and then to quit. Set a } \\
\text { cessation date to quit } \\
\text { directly. }\end{array}$} & \multirow{2}{*}{$\begin{array}{l}\text { Nicotine } \\
\text { lozenges }\end{array}$} & 4.0 & 23.6 & \multirow[t]{2}{*}{2010} & \multirow[t]{2}{*}{5} \\
\hline & Abrupt & 299 & $48.0 \pm 12$ & $23.0 \pm 9$ & & & 7.0 & 20.7 & & \\
\hline \multirow[t]{2}{*}{ Etter ${ }^{16}$} & Gradual & 154 & 42.0 & 24.0 & \multirow{2}{*}{$\begin{array}{l}\text { Reduced by } 50 \% \text { in } \\
\text { four weeks, and then } \\
\text { to quit. Set a cessation } \\
\text { date to quit directly. }\end{array}$} & \multirow{2}{*}{$\begin{array}{l}\text { Nicotine } \\
\text { gum }\end{array}$} & 20.1 & 11.0 & \multirow[t]{2}{*}{2009} & \multirow[t]{2}{*}{5} \\
\hline & Abrupt & 160 & 44.1 & 23.4 & & & 19.4 & 12.5 & & \\
\hline
\end{tabular}

NRT: nicotine replacement therapy. 
Figure 2. Trials of gradual vs abrupt group: funnel plot of prolonged abstinence rate

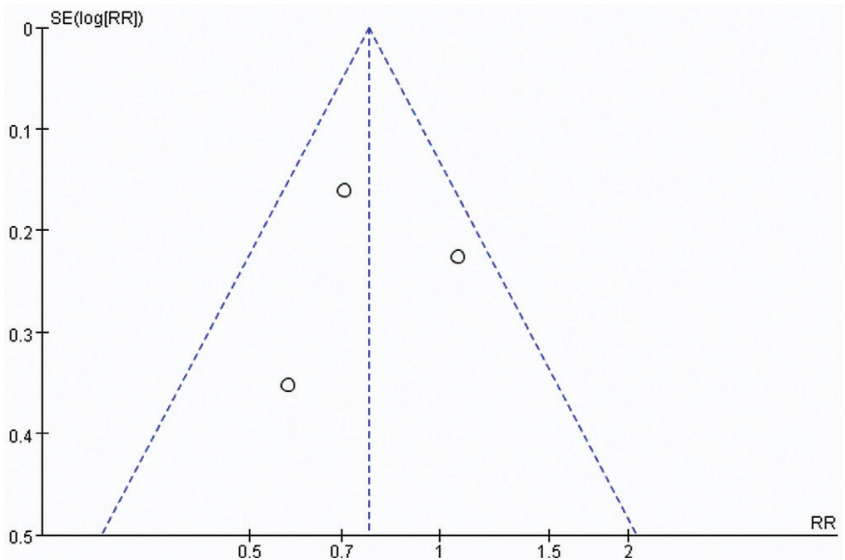

SE: standard error, RR: relative risk.
Prolonged and 7-day CO-verified abstinence rates In all, 3 trials including 1607 participants provided useful data on prolonged and 7-day CO-verified abstinence at the follow-up at 6 or 12 months. The prolonged abstinence in the gradual and abrupt groups were 97 of 793 and 130 of 814 participants, respectively. The prolonged abstinence rate of the gradual group was significantly lower than that of the abrupt group ( $R R=0.77,95 \%$ CI: 0.61-0.98; $p=0.03$ ) (Figure 3). The result of 7-day smoking cessation rate was also lower in the gradual group $(\mathrm{RR}=0.76,95 \%$ CI: 0.61-0.94; $\mathrm{p}=0.01$ ) (Figure 4 ). In addition, the authors of this paper compared all reported adverse events between the groups. However, there were insufficient data to analyze the outcome.

Figure 3. Trials of gradual vs abrupt group: forest plot of prolonged abstinence rate

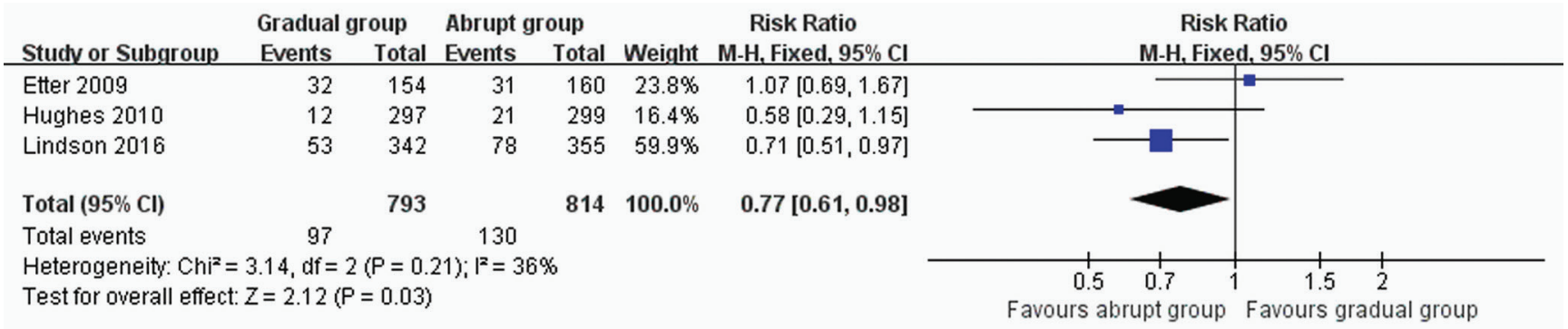

M-H: Mantel-Haenszel, Cl: confidence interval.

Figure 4. Trials of gradual vs abrupt group: forest plot of 7-day abstinence rate

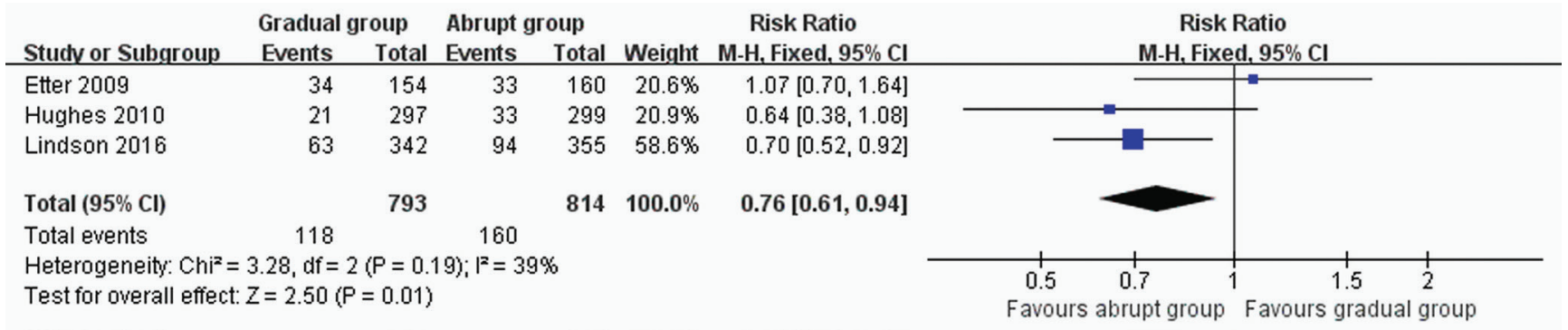

M-H: Mantel-Haenszel, Cl: confidence interval.

\section{DISCUSSION}

NRT aims to reduce motivation to smoke and the physiological and psychomotor withdrawal symptoms often experienced during an attempt to stop smoking, and thus increase the likelihood of remaining abstinent ${ }^{17}$. Nicotine replacement products are formulated for absorption through the oral or nasal mucosa (chewing-gum, lozenges, sublingual tablets, inhaler/inhalator, spray) or through the skin (transdermal patches). The evidence that NRT helps some people to stop smoking is now well accepted, and many clinical guidelines recommend NRT as a firstline treatment for people seeking pharmacological help to stop smoking ${ }^{10,11,18-20}$. Consequently, NRT plays a very important role in the smoking cessation process.

This meta-analysis showed that the prolonged and 7-day abstinence rates of the combination of NRT and 
gradual method to quit were significantly lower than the combination of NRT and abrupt method. This is not consistent with results of previous meta-analyses by Lindson-Hawley et al. ${ }^{21}$ who found that the overall rate ratio for abstinence for reduction versus abrupt cessation was 0.94 (95\% CI: $0.79-1.13 ; \mathrm{p}=0.51$ ). Although they conducted a subgroup analysis of the data, there was still no significant difference in abstinence rate between the two groups. The metaanalysis included ten trials; it was found that most of these trials were self-reported results. Studies have shown that the self-reported quitting rates are much higher than the smoking cessation rates detected by end-expiratory $\mathrm{CO}$ concentration ${ }^{14-16}$. The authenticity of the self-report is relatively low. Other possible reasons for this diversity are inconsistent intervention between trials, and inclusion of non-RCTs and some relatively poor-quality trials.

From the result of this meta-analysis, it can be inferred that smokers who choose the abrupt method are more likely to quit smoking. It is consistent with the population data surveys of Cheong et al. ${ }^{2}$, and West and Brown ${ }^{22}$. Some experts have suggested this is because smokers who chose to delay lose motivation to quit ${ }^{23-25}$. Another explanation could be that the motivation to quit predicts the means by which persons quit and those who are less motivated select gradual cessation ${ }^{9,26}$. It is important to maintain continuous and sufficient motivation to quit smoking. Future studies could examine this possibility.

In this meta-analysis only RCTs were eligible, and these studies were relatively well designed. More than 300 participants were included in each study (ranging from 314 to 697). To ensure the reliability of the results, end-expiratory $\mathrm{CO}$ concentrations were only used to check whether the participant had quit smoking, and self-reported studies were excluded. No significant heterogeneity among the different studies existed when prolonged and 7-day abstinence rates were evaluated. To the best knowledge of the authors, the present meta-analysis is the first comparison of nicotine replacement therapy combined with two different smoking cessation methods.

\section{Limitations}

Limitations of this meta-analysis are the low number of articles included while the follow-up time of each article is relatively short. Also, insufficient data are available to enable us to analyze adverse events and perform subgroup analysis of smoking cessation results.

\section{CONCLUSIONS}

Compared with the combination of NRT and abrupt method to quit, the smoking cessation rate of the combination of NRT and gradual method is significantly lower. No significant adverse events were found in either group.

\section{REFERENCES}

1. Ezzati M, Lopez AD. Estimates of global mortality attributable to smoking in 2000. Lancet. 2003;362(9387):847-852. doi:10.1016/s0140-6736(03)14338-3.

2. Cheong Y, Yong HH, Borland R. Does how you quit affect success? A comparison between abrupt and gradual methods using data from the International Tobacco Control Policy Evaluation Study. Nicotine Tob Res. 2007;9(8):801-810. doi:10.1080/14622200701484961.

3. Hughes JR. Smokers who choose to quit gradually versus abruptly. Addiction. 2007;102(8):1326-1327. doi:10.1111/j.1360-0443.2007.01948.x.

4. Tobacco Use and Dependence Guideline Panel. Treating Tobacco Use and Dependence: 2008 Update. Rockville, MD: US Department of Health and Human Services; 2008.

5. New Zealand Ministry of Health. New Zealand Smoking Cessation Guidelines. Wellington, New Zealand: Ministry of Health; 2007. https://www. treatobacco. net/ en/ uploads/ documents/ Treatment\% 20 Guidelines/ New\%20Zealand\%20treatment\%20guidelines\%20in\% 20 English\% 202007. Pdf. Accessed November 1, 2018.

6. Society for Research on Nicotine and Tobacco. National treatment guidelines. Madison, Wisconsin: Society for Research on Nicotine and Tobacco; 2012. https://www. test.bwa-communication.co.uk/treatobacco/test/en/ page_224.php. Accessed February 18, 2016.

7. West R. Behaviour change in theory and in real life. London, UK: University College London; 2008. https://www.rjwest.co.uk/downloadfile. php?filename $=$ uploads $/ 080424$ stockholm.ppt. Accessed September 19, 2013.

8. Fiore MC, Novotny TE, Pierce JP, et al. Methods used to quit smoking in the United States. Do cessation programs help? JAMA. 1990;263(20):2760-2765. doi:10.1001/jama.1990.03440200064024

9. Peters EN, Hughes JR, Callas PW, Solomon LJ. Goals indicate motivation to quit smoking. Addiction. 2007;102(7):11581163. doi:10.1111/j.1360-0443.2007.01870.x

10. Clinical Practice Guideline Treating Tobacco Use and Dependence 2008 Update Panel, Liaisons, and Staff. A clinical practice guideline for treating tobacco use 
and dependence: 2008 update. A U.S. Public Health Service report. Am J Prev Med. 2008;35(2):158-176. doi:10.1016/j.amepre.2008.04.009

11. West R, McNeill A, Raw M. Smoking cessation guidelines for health professionals: an update. Health Education Authority. Thorax. 2000;55(12):987-999. doi:10.1136/thorax.55.12.987

12. Higgins JPT, Green S, eds. Cochrane handbook for systematic reviews of interventions. Version 5.1.0. The Cochrane Collaboration; 2011.

13. Jadad AR, Moore RA, Carroll D, et al. Assessing the quality of reports of randomized clinical trials: is blinding necessary? Control Clin Trials. 1996;17(1):112. doi:10.1016/0197-2456(95)00134-4

14. Lindson-Hawley N, Banting M, West R, Michie S, Shinkins B, Aveyard P. Gradual Versus Abrupt Smoking Cessation: A Randomized, Controlled Noninferiority Trial. Ann Intern Med. 2016;164(9):585-592. doi:10.7326/m14-2805

15. Hughes JR, Solomon LJ, Livingston AE, Callas P, Peters EN. A randomized, controlled trial of NRT-aided gradual vs. abrupt cessation in smokers activelytrying to quit. Drug Alcohol Depend. 2010;111(1-2):105-113. doi:10.1016/j.drugalcdep.2010.04.007

16. Etter JF, Huguelet P, Perneger TV, Cornuz J. Nicotine gum treatment before smoking cessation: a randomized trial. Arch Intern Med. 2009;169(11):1028-1034. doi:10.1001/archinternmed.2009.12

17. West R, Shiffman S. Effect of oral nicotine dosing forms on cigarette withdrawal symptoms and craving: a systematic review. Psychopharmacology. 2001;155(2):115-122. doi:10.1007/s002130100712

18. Zwar N, Borland R, Peters M, et al. Supporting Smoking Cessation: A Guide for Health Professionals. Melbourne: The Royal Australian College of General Practitioners; 2011.

19. McRobbie H, Bullen C, Glover M, et al. New Zealand Smoking Cessation Guidelines. N Z Med J. 2008; 121(1276):57-70.

20. Woolacott NF, Jones L, Forbes CA, et al. The clinical effectiveness and costeffectiveness of bupropion and nicotine replacement therapy for smoking cessation: a systematic review and economic evaluation. Health Technol Assess. 2002;6(16):1-245. doi:10.3310/hta6160

21. Lindson-Hawley N, Aveyard P, Hughes JR. Reduction versus abrupt cessation in smokers who want to quit. Cochrane Database Syst Rev. 2012;11:CD008033. doi:10.1002/14651858.CD008033.pub3

22. West R, Brown J. Smoking and smoking cessation in England 2011. London, UK: Smoking in England; 2012. https://www.smokinginengland.info/ downloadfile/?type $=$ sts-documents\&src $=19$. Accessed September 19, 2013.

23. Larabie LG. To what extent do smokers plan quit attempts? Tob Control. 2005;14(6):425-428. doi:10.1136/tc.2005.013615
24. West R, Sohal T. Catastrophic pathways to smoking cessation: Findings from a national survey. BMJ. 2006;332(7539):458460. doi:10.1136/bmj.38723.573866.ae.

25. Ferguson SG, Shiffman S, Gitchell J, Sembower MA, West R. Unplanned quit attempts - Results from a U.S. sample of smokers and ex-smokers. Nicotine Tob Res. 2009;11(7):827-832. doi:10.1093/ntr/ntp072

26. Wee LH, Shahab L, Bulgiba A, West R. Conflict about quitting predicts the decision to stop smoking gradually or abruptly: evidence from stop smoking clinics in Malaysia. J Smok Cessat. 2011;6(1):37-44. doi:10.1375/jsc.6.1.37
CONFLICTS OF INTEREST Authors have completed and submitted the ICMJE Form for Disclosure of Potential Conflicts of Interest and none was reported.

FUNDING

There was no source of funding for this research.

PROVENANCE AND PEER REVIEW

Not commissioned; externally peer reviewed. 